Temmink, D., Francke, A.L., Hutten, J.B.F., Spreeuwenberg, P., Zee, J. van der, Huyer Abu-Saad, H. Content and outcomes of Dutch nurse clinics for children with asthma.

Journal of Asthma: 38, 2001, nr. 1, p. 73-81

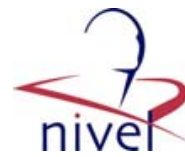

\begin{tabular}{|l|l|}
\hline Postprint Version & 1.0 \\
\hline Journal website & $\underline{\text { http://dx.doi.org }}$ \\
\hline Pubmed link & $\begin{array}{l}\text { http://www.ncbi.nlm.nih.gov/entrez/query.fcgi?.cmd=Retrieve\&db=pubmed\&dop } \\
\text { t=Abstract\&list_uids=11256557\&query_hl=33\&itool=pubmed_docsum }\end{array}$ \\
\hline DOI & \begin{tabular}{l} 
10.1081/JAS-100000024 \\
\hline
\end{tabular}
\end{tabular}

\title{
Content and Outcomes of Dutch Nurse Clinics for Children with Asthma
}

D. Temmink, M.N., R.N., ${ }^{1}$ A. L. Francke, Ph.D., R.N., ${ }^{1}$ J. B. F. Hutten, Ph.D., ${ }^{1}$ P. SPREeuWenBerg, M.A., ${ }^{1}$ J. VAN DER ZEE, PH.D., ${ }^{1}$ AND H. HUYer ABU-SAAD, PH.D., R.N. ${ }^{2}$

${ }^{1}$ Netherlands Institute of Primary Health Care (NIVEL), Utrecht, The Netherlands

${ }^{2}$ Department of Nursing Science, Faculty of Health Sciences, Maastricht University, Maastricht, The Netherlands

Address correspondence to: D. Temmink, NIVEL, P.O. Box 1568, 3500 BN Utrecht, The Netherlands. Fax: (+31) 30-2729729. E-mail: d.temmink@nivel.nl

\begin{abstract}
Dutch specialist asthma nurses run extramural and transmural nurse clinics for children with asthma. Extramural clinics are run under the responsibility and in the premises of a home care organization. Transmural clinics are run in an outpatient clinic in close collaboration and joint responsibility between home care organizations and hospitals.

Effects of and differences between these clinics were determined by using a quasiexperimental design. Visiting a nurse clinic appears to result in a reduced information need and reduced use of health care services. Parents of asthmatic children visiting transmural nurse clinics appeared to have a lower information need than those attending extramural nurse clinics.
\end{abstract}

\section{INTRODUCTION}

In the Netherlands a growing number of nurses have a specific focus on care for asthmatic children $(1,2)$. These nurses are often employed by home care organizations, and one of their tasks is to run nurse clinics for such children. In these clinics, specialist nurses provide illness-related information about topics such as inhaler techniques and asthma preventers and relievers.

Dutch health care is traditionally a two-tiered system including both office-based primary care services, such as home care, and hospital-based specialty care services $(3,4)$. In keeping with this health care system, nurse clinics in the Netherlands are employed in both home care and hospital. Extramural nurse clinics have a rather long tradition in Dutch health care and are run at the responsibility and in the premises of a home care organization. So-called transmural nurse clinics are more recent and have been implemented in Dutch hospital outpatient departments in the last 5 years. In 1996, 11 such clinics were established in the Netherlands (5). In transmural nurse clinics, care is provided on the basis of close collaboration and joint responsibility between home care organizations and hospitals (5).

Implementing transmural nurse clinics depends to a large extent on the existing health care facilities for children with asthma. Regions in which extramural nurse clinics are operational will not establish transmural nurse clinics as well. However, in regions where there are no nurse clinics for asthmatic children, a transmural nurse clinic may be established because of the current interest in transmural care innovations in the Dutch health care system.

Despite the organizational differences between extramural and transmural nurse clinics, the two kinds of clinics have comparable objectives. Extramural and transmural nurse clinics aim to provide 
Temmink, D., Francke, A.L., Hutten, J.B.F., Spreeuwenberg, P., Zee, J. van der, Huyer Abu-Saad, H. Content and outcomes of Dutch nurse clinics for children with asthma.

Journal of Asthma: 38, 2001, nr. 1, p. 73-81

asthmatic children and their parents with information on, for instance, how to deal with asthma in daily life or how to use the medication.

Nurse clinics for asthmatics have also been established in the United Kingdom and Ireland (6-12).

These clinics are often implemented in general practice and are, like Dutch extramural and transmural nurse clinics, designed primarily to provide patients with information about how to deal with their asthma in daily life.

Several studies generally record a positive impact when education is provided to asthmatics. For instance, Taggart et al. (13) using a quasi-experimental design, evaluated an inpatient hospital-based self-management education program comprising written and audiovisual materials and interpersonal communication with a nurse. This study showed that inpatient hospital-based education reduces asthmatic children's use of health care services. A quasi-experimental evaluation study by Pérez et al. (14) showed that a self-management education program (with separate sessions for parents and asthmatic children) given by a (nurse) allergy specialist in the hospital resulted in significant positive effects on children's and parents' asthma knowledge.

Whether the comparable objectives of Dutch transmural and extramural nurse clinics translate into comparable patients attending the clinics and comparable content in the nursing care provided remains unclear. Furthermore, it is doubtful whether the positive results of asthma education programs in general also apply to asthma nurse clinics. Nurse clinics run by specialist asthma nurses are regarded as providing more time and opportunity for patients to increase their knowledge of the disease $(6,11)$. In addition, attending a nurse clinic is expected to reduce asthmatic children's and their parents' use of health care services. The number of contacts with general practitioners, for example, might be reduced following attendance at a nurse clinic. However, reliable insight into the content and effectiveness of asthma nurse clinics in terms of patients' need for information and their use of health care services is lacking $(6,10)$. Moreover, there is no evidence as to the preferred organizational structure for nurse clinics $(6,15)$.

Consequently, the aim of this study is to explore differences in children attending the clinics and differences in the content of care given by Dutch specialist nurses running transmural or extramural clinics. The effects of visiting such a clinic on (parents of) asthmatic children's need for asthmarelated information and their use of health care services are also determined. Finally, this study explores differences in outcomes between Dutch extramural and transmural nurse clinics. The following research questions are addressed in this article:

1. Do transmural and extramural nurse clinics differ with regard to the characteristics of the attending asthmatic children and their parents (e.g., age, gender, duration of complaints, severity of asthma, and level of education)?

2. Do transmural and extramural nurse clinics differ with regard to the nursing care provided (e.g., referral to the clinic, number and duration of contacts, care demands and activities)?

3. What is the effect of visiting a nurse clinic on (parents of) asthmatic children's need for asthmarelated information and use of health care services, more specifically the number of contacts with other health care professionals and the number of admissions in hospitals and other institutions?

4. Is there a difference in outcomes between transmural and extramural nurse clinics with regard to parents' need for asthma-related information and asthmatic children's use of health care services?

\section{METHODS}

\section{Design and Measurement Points}

To answer the research questions, a pretest-posttest, nonrandomized control group design was used. Two groups of parents ${ }^{1}$ participated in the study. The first group comprised parents who attended a transmural nurse clinic; the other group comprised parents who attended an extramural nurse clinic. Both groups were approached for three telephone interviews within 6 months. The first telephone interview with parents was conducted 1-4 days before parent and child were to attend a nurse clinic (T0). The second interview took place 6 weeks after their first appointment at the nurse clinic (T1),

\footnotetext{
${ }^{1}$ The term "parent" will be used henceforth to indicate both asthmatic children and their parents.
} 
Temmink, D., Francke, A.L., Hutten, J.B.F., Spreeuwenberg, P., Zee, J. van der, Huyer Abu-Saad, H. Content and outcomes of Dutch nurse clinics for children with asthma.

Journal of Asthma: 38, 2001, nr. 1, p. 73-81

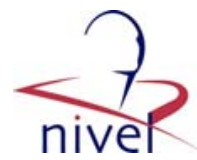

and the third interview was conducted 6 months after their first appointment at the nurse clinic (T2).

The duration of the telephone interviews ranged from about 15 to 30 minutes.

\section{Locations and Sample}

The study was conducted at six locations in the Netherlands. At four of the locations a home care organization and a hospital collaborated closely and had joint responsibility for a transmural nurse clinic. All four transmural nurse clinics were held at a hospital outpatient department by specialist asthma nurses who were employed by a home care organization. At two of the locations (each with three sublocations), six extramural nurse clinics for asthmatic children were held by specialist asthma nurses who were also employed by a home care organization. The home care organization bore the sole responsibility for the extramural clinics.

The following inclusion criteria were used in this study:

1. The child has a diagnosis of chronic nonspecific lung diseases (e.g., asthma or chronic obstructive pulmonary disease.)

2. The child is under 14 years of age.

3. Parents and child have had no previous contact with a specialist asthma nurse.

4. At least one parent is able to speak Dutch.

5. There is telephone access.

Permission for patient recruitment was obtained from ethics committees and the professionals involved. Parents who met the inclusion criteria were invited to participate in the study by the secretariat of the particular clinic at the time they made an appointment at the clinic. In addition to this direct request, the parents were given an information letter in which goals and procedures of the study were explained. Those who chose to participate gave their written consent and were approached for a telephone interview.

Between April 1996 and February 1998 a total of 237 respondents were included in the study; 152 attended a transmural nurse clinic, and 85 attended an extramural nurse clinic. Thirteen of the 152 parents attending a transmural nurse clinic and 22 of the 85 parents attending an extramural nurse clinic dropped out of the study. The reasons for dropping out were that they did not want to or could not be interviewed by telephone for posttest measurement $(n=18)$, it appeared that the parents had not attended the clinic during the study $(n=14)$, and illness or other family circumstances $(n=3)$. Consequently, information is available about 139 parents (91\% response) and 63 parents (74\% response) who attended a transmural or extramural nurse clinic, respectively.

\section{Variables and Instruments}

During the first measurement (T0), the following background characteristics of parents and their asthmatic children were gathered: age and gender, duration of the child's asthma-related complaints, and gender and educational level of the parent (see Table 1).

\section{[ TABLE 1 ]}

During the research period of 6 months, specialist asthma nurses running either a transmural or an extramural nurse clinic filled in a registration form for each child. The specialist nurse registered information on the content of the nursing care provided, namely, the referral to the nurse clinic, the number and duration of contacts with the child and parent, care demands made on the nurse, and the nursing care carried out (see Table 2). The severity of the child's asthma was registered by the nurse during the first contact with the child. Following Van Es (16), four categories based on the degree of exacerbation and the prescribed amount and type of medication were used: mild (stable with less than six levels of exacerbation annually), moderate (stable with $\leq 400 \mu \mathrm{g}$ inhaled corticosteroids per day), severe (>400 $\mu$ g inhaled corticosteroids per day), and severity unknown by the nurse (see Table 2).

\section{[ TABLE 2 ]}


Temmink, D., Francke, A.L., Hutten, J.B.F., Spreeuwenberg, P., Zee, J. van der, Huyer Abu-Saad, H. Content and outcomes of Dutch nurse clinics for children with asthma.

Journal of Asthma: 38, 2001, nr. 1, p. 73-81

To gain insight into parents' need for asthma-related information, at all measurements, parents were asked about the topics for which they required asthma-related information. The response categories used in this question are displayed in Table 3.

\section{[ TABLE 3 ]}

To determine asthmatic children's use of health care facilities, parents were asked at T0 and T2 to rate their child's number of asthma-related contacts with health care professionals (general practitioner, physiotherapist, or pediatrician) during the last six months (see Table 4). Parents were also asked to give the number of times their child had been admitted to hospital or other health care institutions during the last 6 months. Reason for not asking this question at T1 was that changes in patients' use of health care facilities could not be expected in the 6-week period between T0 and T1.

\section{[ TABLE 4 ]}

\section{Analyses}

Differences between the two groups in patient characteristics (Table 1) and the content of the care provided (Table 2) were determined by using student's $t$-test for continuous data, the chi-squared test for nominal data, and the Mann-Whitney test for ordinal data.

To determine differences between measurements and research groups in information needs and use of health care facilities, multiple linear regression analyses and Analysis of covariance multivariable (MANCOVAs) for repeated measures were used for continuous data. Since multiple linear regression analyses and MANCOVAs showed comparable results, only the output of linear regression analysis will be reported in this article. Dichotomous data were analyzed by using multiple logistic regression analyses. In all analyses, differences between the two groups and measurements were tested after controlling for children's and parents' background characteristics as displayed in Table 1 and interaction terms between measurements and conditions.

\section{RESULTS}

\section{Patient Characteristics}

Table 1 shows that the two groups were comparable in most patient characteristics. The children had a mean age of 5 years, $60 \%$ were male, and the mean duration of the disease was 3 years in both groups. Most of the parents had primary or secondary education; $95 \%$ were female. A significant difference in the severity of children's asthma was found between the two groups. Children attending an extramural nurse clinic appeared to have less severe asthma than children attending a transmural nurse clinic. Furthermore, it appeared that nurses running an extramural nurse clinic more frequently did not know the severity of the child's asthma (Table 1).

\section{Nursing Contacts}

The person who referred children to the specialized nurse was significantly different for the two groups. Most of the parents attending a transmural nurse clinic were referred by a pediatrician, while parents attending an extramural nurse clinic were either referred by their pediatrician or a general practitioner or had contacted the nurse on their own initiative (Table 2).

As regards the mean number of contacts between parents and specialist nurses, no significant difference was found. Parents in both groups contacted the specialist nurse more than twice on average (Table 2). However, the duration of these contacts appeared to be significantly longer in the extramural situation. Parents attending a transmural nurse clinic visited the specialist nurse for $\mathbf{4 0}$ minutes on average, while for parents attending an extramural nurse clinic, this duration was more than 50 minutes on average.

Both similarities and differences between the two groups were found with regard to the care demands made upon the specialist nurses. In both groups, parents made more than one care request relating to their living environment, for example, "Do we have adequate curtains or bedcovers in my child's bedroom?” However, it appeared that parents attending a transmural nurse clinic made significantly 
Temmink, D., Francke, A.L., Hutten, J.B.F., Spreeuwenberg, P., Zee, J. van der, Huyer Abu-Saad, H. Content and outcomes of Dutch nurse clinics for children with asthma.

Journal of Asthma: 38, 2001, nr. 1, p. 73-81

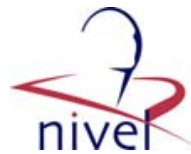

more frequent care demands relating to the use of medication, dealing with asthma in daily life (for instance, during holidays or at school), and smoking (Table 2).

With respect to the care activities of the specialist nurses, it was found that nurses running transmural nurse clinics more often provided psychosocial support to parents and their children compared to those running extramural nurse clinics.

\section{Need for Asthma-Related Information}

Table 3 shows that $62 \%$ of the total number of parents participating indicated at $\mathrm{T} 0$, that they needed some kind of additional information about asthma. This percentage decreased during the research period to $23 \%$ at $\mathrm{T} 1$ and decreased further to $10 \%$ at T2. Topics about which parents needed more information included, for example, how to request practical aids or adaptations, asthma itself, or how to handle their child's asthma in daily life. The mean number of asthma-related topics mentioned by the total group of parents at T0 was 1.3; this mean number declined at T1 and T2 to 0.3 and 0.2 , respectively.

Logistic regression analysis showed that the differences in time with respect to parents' need for information about requesting practical aids or adaptations, asthma in general, asthma in daily life, and the use of medication were significant (Table 3). Logistic regression analysis also indicated a significant difference between parents in the two conditions with respect to their need for information about requesting practical aids or adaptations in the living environment and information about asthma in general. Parents who attended a transmural nurse clinic reported significantly fewer needs concerning this kind of information.

Furthermore, regression analyses showed that the total number of topics about which parents needed information was significantly lower for parents in the transmural group (Table 5).

\section{[ TABLE 5 ]}

\section{Use of Health Care Services}

Table 4 displays childrens' average number of contacts with professionals (exclusively the specialist asthma nurse) and their average number of hospital admissions for the research conditions separately and for the total group. It appeared that children attending either a transmural or an extramural nurse clinic contacted health care professionals at T2 less frequently compared to T0. Linear regression analyses indicated that the total number of contacts with health care professionals and, more specifically, general practitioners significantly decreased in the total group of children. Furthermore, it appeared that this drop of the number of contacts with health care professionals did not significantly differ between the transmural and extramural condition (Table 5).

With regard to the average number of hospital admissions, it appeared that children in this study were seldom admitted to a hospital during the research period (Table 4). Significant differences in this respect were not found, either among the measurements or among research conditions.

\section{CONCLUSIONS AND DISCUSSION}

In the Netherlands, two kinds of nurse clinics for children with asthma have been established. The first kind are so-called extramural nurse clinics, which are run under the responsibility and in the premises of a home care organization. The second kind, so-called transmural nurse clinics, have only recently been established in the Netherlands. These transmural nurse clinics are provided on the basis of close collaboration and joint responsibility between home care organizations and hospitals. This article gives insight into whether the patients attending these two kinds of clinics and the content of the nursing care provided in these clinics are comparable. Furthermore, we determine whether attending Dutch nurse clinics results in changes in parents of asthmatic children's need for asthmarelated information and asthmatic children's use of health care services. Finally, insight is given into whether the organizational difference between transmural and extramural nurse clinics leads to different outcomes.

In this study, almost no differences were found between children with asthma and their parents attending transmural or extramural nurse clinics. However, it appeared that in extramural nurse clinics, children had less severe asthma and that the severity of the children's asthma was often not known by 
Temmink, D., Francke, A.L., Hutten, J.B.F., Spreeuwenberg, P., Zee, J. van der, Huyer Abu-Saad, H. Content and outcomes of Dutch nurse clinics for children with asthma.

Journal of Asthma: 38, 2001, nr. 1, p. 73-81

the nurses running the clinics. In line with these results, it was found that the content of the care provided in transmural and extramural nurse clinics appeared to differ depending on the person referring to the clinic (pediatrician in transmural clinic vs. general practitioner, pediatrician, or own initiative). Also with respect to the duration of the nursing contacts (significantly longer in extramural clinics), parents' care demands (in transmural nurse clinics more frequent demands concerning the use of medication, dealing with asthma, and smoking), and nurses' care activities (in transmural nurse clinics nurses more often provided psychosocial support), differences were found.

Especially the fact that in extramural nurse clinics, parents contact the specialist nurse at their own initiative seems to be related to the unknown (by the nurse) severity of the child's asthma. These two results, combined with the fact that the groups of asthmatic children in regions in which extramural and transmural nurse clinics are operational are comparable, point in the direction that structural referrals of children with asthma to an extramural nurse clinic could be improved in the future.

In line with our expectation, this study indicated that after attending a nurse clinic, parents had significantly decreased needs for asthma-related information. Furthermore, it appeared that this decline in parents' needs for asthma-related information was greater in transmural than in extramural nurse clinics.

In other research too, in which information was provided to children with asthma or their parents, positive effects on information requirement were found. For instance, Mesters (17) evaluated a multidisciplinary education protocol for primary care professionals (general practitioners, community nurses, asthma nurses, and doctors in child health centers). This experimental study concluded that when the protocol was used, parents' knowledge about asthma improved significantly. Research in hospital settings also indicated positive effects of asthma-related information given by specialist nurses. Donaghy (12) compared a group of asthmatics who received only instruction from a doctor with a comparable group who received an additional individual education program conducted by an asthma nurse specialist. The latter study demonstrated that additional asthma education provided by a nurse specialist improves patients' understanding of asthma. When interpreting these results of others, it should be kept in mind that in the current study, parents' needs for information were measured, while in other research, parents' knowledge about or understanding of asthma was determined.

The expectation that attending a nurse clinic would lead to a decrease in asthmatic children's use of health care services is also confirmed in this study. However, with respect to the organizational differences between transmural and extramural nurse clinics, no differences were found with regard to the decline in the number of hospital admissions and number of contacts with health care professionals. Colland's study (18) also concluded that asthmatic children who followed a behavioral self-management program (consisting of 10 weekly 1-hour education sessions with a group of six to eight children) had a lower health care consumption. Other research also indicated that the implementation of an education program for asthmatic patients, which are mainly informative, resulted in a decline in the use of health care services $(13,17,19-22)$. Consequently, on the basis of the current underlying study and other research, it can be concluded that education programs for asthmatics in general and nurse clinics for asthmatic children in particular result in a decline in asthmatic patients' use of health care services. The organizational context in which the education is provided does not seem to influence this use.

These results bring us to the question of why transmural nurse clinics for children with asthma have recently been implemented in Dutch health care. Reasons given by policymakers are often formulated in terms such as improvement of quality and continuity of care and efficiency (reduction of health care costs). In this study, health care costs were not measured. However, our results on patients' use of health care services do not point in the direction of lower cost for the care provided in transmural nurse clinics compared with the care provided in traditional extramural nurse clinics. With respect to the quality and continuity of care, it should be noted that from another part of this study, it was concluded that there were no significant differences between the two kinds of nurse clinics in parents' positive perceptions about the quality and continuity of the care provided (23). It seems, therefore, that the characteristics of health care regions are the decisive factors for implementing or continuing transmural or extramural nurse clinics. 
Temmink, D., Francke, A.L., Hutten, J.B.F., Spreeuwenberg, P., Zee, J. van der, Huyer Abu-Saad, H. Content and outcomes of Dutch nurse clinics for children with asthma.

Journal of Asthma: 38, 2001, nr. 1, p. 73-81

\section{LIMITATIONS OF THE STUDY}

It should be remembered that the comparison of the outcomes in this study was based on the data of a limited number of transmural and extramural nurse clinics. However, in 1996, only 11 transmural nurse clinics for children with asthma, with comparable content, were established in the Netherlands (4). Consequently, the results for transmural nurse clinics probably apply to all Dutch transmural nurse clinics. The precise number of extramural nurse clinics established in the Netherlands is unclear. However, it is assumed that this number is low, and it can therefore be stated that the results of the six extramural nurse clinics in this study also apply to other extramural nurse clinics for children with asthma in the Netherlands.

In this study, data about parents and children with asthma who cannot attend a nurse clinic but receive regular care only were not available. However, such information can give insight into additional positive effects of visiting a nurse clinic. Accordingly, it is recommended a control group receiving only regular care be included in future research.

Furthermore, as a result of including all children with asthma instead of making a distinction in the severity of their asthma, the data obtained in this study could not be used for analyzing differences between children who suffered severe, moderate, or mild asthma. It is assumed that the severity of the illness influences patients' demands. Consequently, future research in which the effects of visiting nurse clinics on specific groups of children with asthma can be tested is recommended.

\section{ACKNOWLEDGMENTS}

This study was supported by a grant from the Dutch Ministry of Health, Welfare and Sport Affairs. We thank the parents of asthmatic children, nurses, and pediatricians for participating in this study and Anneke Kaper for her help in collecting and entering the data.

\section{TABLES}

Table 1

Background Characteristics of Parents and Their Children in Both Research Conditions

\begin{tabular}{|c|c|c|c|}
\hline & $\begin{array}{l}\text { Transmural Condition } \\
\qquad(n=139)\end{array}$ & $\begin{array}{l}\text { Extramural Condition } \\
\qquad(n=63)\end{array}$ & $p$ \\
\hline Age of child in years ${ }^{a}$ & $4.5(3.1)$ & $5.1(3.5)$ & n.s. \\
\hline Gender of child (male) & $81(58 \%)$ & $36(57 \%)$ & n.s. \\
\hline Gender of parent (female) & $131(94 \%)$ & $56(89 \%)$ & n.s. \\
\hline Duration of complaints in years ${ }^{a}$ & $2.7(2.3)$ & $3.3(2.9)$ & n.s. \\
\hline Severity of asthma: & & & * \\
\hline Mild & $13(9 \%)$ & $11(17 \%)$ & \\
\hline Moderate & $71(51 \%)$ & $18(29 \%)$ & \\
\hline Severe & $45(32 \%)$ & $3(5 \%)$ & \\
\hline Unknown & $1(1 \%)$ & $26(41 \%)$ & \\
\hline Level of education of parent: & & & n.s. \\
\hline Lower & $60(43 \%)$ & $24(38 \%)$ & \\
\hline Middle & $59(42 \%)$ & $29(46 \%)$ & \\
\hline Higher & $19(14 \%)$ & $10(16 \%)$ & \\
\hline
\end{tabular}

Missing values: Age of child in years ( 1 in transmural group, 4 in extramural group), gender of child (4 in transmural group, 1 in extramural group), gender of parent ( 3 in transmural group, 1 in extramural group), duration of complaints (10 in transmural group), severity of asthma (9 in transmural group, 5 in extramural group), level of education of parent ( 1 in transmural group).

${ }^{a}$ Mean (S.D.)

* $p \leq 0.05$.

n.s. $=$ not significant. 
Temmink, D., Francke, A.L., Hutten, J.B.F., Spreeuwenberg, P., Zee, J. van der, Huyer Abu-Saad, H. Content and outcomes of Dutch nurse clinics for children with asthma.

Journal of Asthma: 38, 2001, nr. 1, p. 73-81

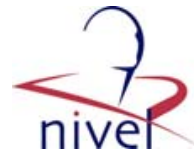

Table 2

Content of the Nursing Care Provided in Transmural and Extramural Nurse Clinics

\begin{tabular}{|c|c|c|c|}
\hline & $\begin{array}{l}\text { Transmural Condition } \\
\qquad(n=139)\end{array}$ & $\begin{array}{l}\text { Extramural Condition } \\
\qquad(n=63)\end{array}$ & $p$ \\
\hline \multicolumn{4}{|l|}{ Referral to the nurse clinic: } \\
\hline Pediatrician & $96 \%$ & $35 \%$ & ** \\
\hline General practitioner & $4 \%$ & $30 \%$ & ** \\
\hline Contacted on own initiative & $0 \%$ & $25 \%$ & ** \\
\hline Number of contacts per child, mean (S.D.) & $2.4(0.7)$ & $2.4(1.1)$ & n.s. \\
\hline Duration of contacts in minutes, mean (S.D.) & $38.2(8.7)$ & $51.8(11.0)$ & ** \\
\hline \multicolumn{4}{|c|}{ Topics of care demands posed to the nurse, mean (S.D.): } \\
\hline Living environment/housing improvement & $1.6(0.7)$ & $1.5(0.8)$ & n.s. \\
\hline Medication use & $1.8(0.7)$ & $1.0(0.8)$ & ** \\
\hline Dealing with asthma & $1.7(0.7)$ & $1.0(0.7)$ & ** \\
\hline Smoking & $0.9(0.8)$ & $0.5(0.8)$ & ** \\
\hline Family situation & $0.4(0.8)$ & $0.3(0.5)$ & n.s. \\
\hline Others & $0.4(0.7)$ & $0.4(0.8)$ & n.s. \\
\hline \multicolumn{4}{|l|}{ Care activities at the nurse clinic, mean (S.D.): } \\
\hline Education/advice & $2.0(0.6)$ & $1.8(0.8)$ & n.s. \\
\hline Psychosocial support & $1.5(1.0)$ & $0.6(0.9)$ & $* *$ \\
\hline History taking & $1.0(0.7)$ & $1.0(0.6)$ & n.s. \\
\hline Others & $0.07(0.3)$ & $0.06(0.3)$ & n.s. \\
\hline
\end{tabular}

* $p \leq 0.05$.

** $p \leq 0.01$.

n.s. $=$ not significant.

Table 3

Information Needs of Parents at T0, T1, and T2 for the Two Conditions Separate and for the Total Group

\begin{tabular}{|c|c|c|c|c|c|c|c|c|c|}
\hline & \multicolumn{3}{|c|}{$\begin{array}{l}\text { Transmural Condition } \\
\qquad(n=139)\end{array}$} & \multicolumn{3}{|c|}{$\begin{array}{l}\text { Extramural Condition } \\
\qquad(n=63)\end{array}$} & \multicolumn{3}{|c|}{$\begin{array}{l}\text { Total Group } \\
(n=202)\end{array}$} \\
\hline & T0 & $\mathrm{T} 1$ & $\mathrm{~T} 2$ & T0 & $\mathrm{T} 1$ & $\mathrm{~T} 2$ & T0 & $\mathrm{T} 1$ & $\mathrm{~T} 2$ \\
\hline $\begin{array}{l}\text { Need for some kind of information } \\
\text { about asthma }{ }^{a, b}\end{array}$ & $55 \%$ & $25 \%$ & $9 \%$ & $76 \%$ & $19 \%$ & $13 \%$ & $62 \%$ & $23 \% *$ & $10 \% *$ \\
\hline \multicolumn{10}{|l|}{ Need for information about: } \\
\hline Requesting practical aids/adaptations $^{a}$ & $27 \%$ & $10 \%$ & $2 \%$ & $54 \%$ & $11 \%$ & $5 \%$ & $36 \%$ & $10 \% *$ & $3 \% *$ \\
\hline Asthma in general $^{a}$ & $22 \%$ & $4 \%$ & $3 \%$ & $41 \%$ & $3 \%$ & $5 \%$ & $28 \%$ & $4 \% *$ & $4 \% *$ \\
\hline Asthma in daily life & $33 \%$ & $4 \%$ & $4 \%$ & $19 \%$ & $2 \%$ & $3 \%$ & $29 \%$ & $3 \% *$ & $4 \% *$ \\
\hline Medication use & $17 \%$ & $8 \%$ & $4 \%$ & $19 \%$ & $0 \%$ & $2 \%$ & $18 \%$ & $5 \%$ & $4 \% *$ \\
\hline Side effects of medication & $5 \%$ & $2 \%$ & $1 \%$ & $10 \%$ & $0 \%$ & $0 \%$ & $6 \%$ & $2 \%$ & $1 \%$ \\
\hline Other & $12 \%$ & $5 \%$ & $1 \%$ & $19 \%$ & $6 \%$ & $2 \%$ & $14 \%$ & $5 \% *$ & $1 \% *$ \\
\hline Total number of topics, mean (S.D. $)^{a, b, c}$ & $\begin{array}{c}1.2 \\
(1.3)\end{array}$ & $\begin{array}{c}0.3 \\
(0.6)\end{array}$ & $\begin{array}{c}0.2 \\
(0.6)\end{array}$ & $\begin{array}{c}1.6 \\
(1.5)\end{array}$ & $\begin{array}{c}0.2 \\
(0.5)\end{array}$ & $\begin{array}{c}0.2 \\
(0.4)\end{array}$ & $\begin{array}{c}1.3 \\
(1.4)\end{array}$ & $\begin{array}{l}0.3^{*} \\
(0.6)\end{array}$ & $\begin{array}{l}0.2^{*} \\
(0.5)\end{array}$ \\
\hline
\end{tabular}

${ }^{a}$ Main effect of condition, $p<0.05$.

${ }^{b}$ Interaction effect condition, $\mathrm{T} 1<0.05$

${ }^{c}$ Interaction effect condition, $\mathrm{T} 2<0.05$.

${ }^{*} p<0.05$ in comparing $\mathrm{T} 1$ or $\mathrm{T} 2$ with $\mathrm{T} 0$ for the total group. 
Temmink, D., Francke, A.L., Hutten, J.B.F., Spreeuwenberg, P., Zee, J. van der, Huyer Abu-Saad, H. Content and outcomes of Dutch nurse clinics for children with asthma.

Journal of Asthma: 38, 2001, nr. 1, p. 73-81

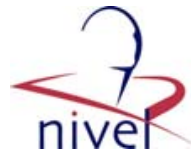

Table 4

Average (and S.D.) Number of Contacts with Other Health Care Professionals and Number of Hospital Admissions at TO and T2 for the Two Conditions Separate and for the Total Group

\begin{tabular}{|c|c|c|c|c|c|c|}
\hline & \multicolumn{2}{|c|}{$\begin{array}{l}\text { Transmural Condition } \\
\qquad(n=139)\end{array}$} & \multicolumn{2}{|c|}{$\begin{array}{l}\text { Extramural Condition } \\
\qquad(n=63)\end{array}$} & \multicolumn{2}{|c|}{$\begin{array}{l}\text { Total Group } \\
(n=202)\end{array}$} \\
\hline & T0 & $\mathrm{T} 2$ & T0 & T2 & T0 & $\mathrm{T} 2$ \\
\hline $\begin{array}{l}\text { Total number of contacts with health } \\
\text { care professionals }\end{array}$ & $7.5(7.8)$ & $3.7(4.5)$ & $7.1(6.5)$ & $4.3(6.0)$ & $7.4(7.4)$ & $3.9(5.0)^{*}$ \\
\hline General practitioner & $4.8(6.2)$ & $1.6(4.1)$ & $5.0(5.4)$ & $2.1(3.6)$ & $4.9(5.9)$ & $1.8(4.0)^{*}$ \\
\hline Pediatrician & $1.9(1.7)$ & $1.8(1.1)$ & $1.7(3.1)$ & $1.5(3.1)$ & $1.8(4.0)$ & $1.7(1.9)$ \\
\hline Physical therapist & $0.04(0.4)$ & $0.2(0.9)$ & $0.02(0.1)$ & $0.3(2.0)$ & $0.04(0.3)$ & $0.2(1.4)$ \\
\hline Others & $0.7(3.0)$ & $0.2(0.7)$ & $0.4(1.3)$ & $0.5(1.5)$ & $0.6(2.6)$ & $0.3(1.0)$ \\
\hline Hospital admissions & $0.2(0.6)$ & $0.1(0.3)$ & $0.2(0.6)$ & $0.1(0.6)$ & $0.2(0.6)$ & $0.06(0.4)$ \\
\hline
\end{tabular}

${ }^{*} p<0.05$ in comparing $\mathrm{T} 2$ with $\mathrm{T} 0$ for the total group.

Table 5

Results of Multiple Linear Regression Analyses

\begin{tabular}{lcc}
\hline Variables in the Equation & $\begin{array}{c}\text { Total Number of Topics About Which } \\
\text { Information is Needed, Beta }\end{array}$ & $\begin{array}{c}\text { Total Number of Contacts } \\
\text { with Professionals, Beta }\end{array}$ \\
\hline Condition (transmural nurse clinic) & $-0.18^{* *}$ & -0.08 \\
Measurement moment (T0) & $-0.63^{* *}$ & $\begin{array}{c}\text { not applicable } \\
\text { T1 }\end{array}$ \\
T2 & $-0.66^{* *}$ & not applicable \\
Condition T1* & $0.22^{* *}$ & -0.07 \\
Condition T2 & $0.18^{*}$ & 0.00 \\
Duration of complaints & 0.01 & 0.04 \\
Level of education of parent (middle): & & -0.06 \\
$\quad$ Lower & -0.01 & -0.01 \\
Higher & 0.02 & $0.11^{*}$ \\
Severity of asthma (moderate): & & -0.09 \\
Mild & 0.06 & 0.04 \\
Severe & 0.06 & 0.05 \\
Unknown & 0.05 & -0.22 \\
Gender of parent (male) & 0.04 & 0.14 \\
Gender of child (female) & 0.02 & 0.11 \\
Age of child in years & 0.01 & 0.27 \\
$R^{2}$ & 0.25 & \\
Adjusted $R^{2}$ & & \\
\hline
\end{tabular}

$* p \leq 0.05$.

${ }^{* *} p \leq 0.01$

\section{REFERENCES}

1. Ketelaars, C. Aftercare and Specialised Community Nursing: Implications for Patients with Chronic Obstructive Pulmonary Disease. Ph.D. Thesis, Rijksuniversiteit Limburg, Maastricht, The Netherlands, 1996.

2. Wiegers, T.A. Evaluatie van Modellen voor Aansluiting Tusen Intramurale Specialistische en Extramurale Verpleegkundige CARA-Zorg voor Kinderen [Evaluation of models for a connection between hospital and home nursing care] (in Dutch); NIVEL: Utrecht, 1991.

3. van der Linden, BA. Transmural Care: Facts and Future. In Health and Health Care in the Netherlands;De Tijdstroom: Utrecht, The Netherlands, 1997, 181-188.

4. Temmink, D.; Francke, A.L.; Hutten, J.B.F.; van der Zee J.; Huyer Abu-Saad, H. Innovations in the Nursing Care of the Chronically Ill: A Litera Review from an International Perspective. J. Adv. Nurs. 2000, 31 (6), 1449-1450.

5. Temmink, D.; Francke, A.L.; Kerkstra, A.; Huyer Abu- Saad, H. Dutch Transmural Nurse Clinics for Chronic Patients: A Descriptive Study. Pat. Educ. Couns. 2000, 39, 177-184.

6. Eastwood, A.J.; Sheldon T.A. Organisation of Asthma Care: What Difference Does It Make? A Systematic Review of the Literature. Qual. Health Care 1996, 5, 134-143. 
Temmink, D., Francke, A.L., Hutten, J.B.F., Spreeuwenberg, P., Zee, J. van der, Huyer Abu-Saad, H. Content and outcomes of Dutch nurse clinics for children with asthma.

Journal of Asthma: 38, 2001, nr. 1, p. 73-81

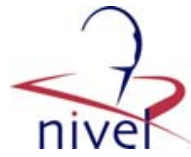

7. Charlton, I.; Charlton, G.; Broomfield, J.; Mullee, M.A. Audit of the Effect of a Nurse Run Asthma

Clinic on Workload and Patient Morbidity in a General Practice. Br. J. Gen. Prac. 1991, 41, 227-231.

8. Charlton, I.; Charlton, G.; Broomfield, J.; Campbell, M. An Evaluation of a Nurse-Run Asthma Clinic in General Practice Using an Attitudes and Morbidity Questionnaire. Fam. Prac. 1992, 9 (2), 154 160.

9. Jones, K.P.; Mullee, M.A. Proactive, Nurse-Run Asthma Care in General Practice Reduces Asthma Morbidity: Scientific Fact or Medical Assumption? Br. J. Gen. Prac. 1995, 45, 497-499.

10. Barnes, G.; Partridge, M.R. Community Asthma Clinics: 1993 Survey of Primary Care by the National Asthma Task Force. Qual. Health Care 1994, 3, 133-136.

11. Dickinson, J.; Hutton, S.; Atkin, A.; Jones, K. Reducing Asthma Morbidity in the Community: The Effect of a Targeted Nurse-Run Asthma Clinic in an English General Practice. Respir. Med. 1997, 91 (10), 634-640.

12. Donaghy, D. The Asthma Specialist and Patient Education. Prof. Nurse 1995, 11, 160-162.

13. Taggart, V.S.; Zuckerman, A.E.; Sly, R.M.; Steinmueller, C.; Newman, G.; O'Brien, R.W.; Schneider, S.; Bellanti, J.A. You Can Control Asthma: Evaluation of an Asthma Education Program for Hospitalized inner-City Children. Pat. Educ. Couns. 1991, 17, 35-47.

14. Pérez, M.G.; Feldman, L.; Caballero, F. Effects of a Self-Management Educational Program for the Control of Childhood Asthma. Pat. Educ. Couns. 1999, 36, 47-55.

15. Droogan, J.; Bannigan, D. Organisation of Asthma Care: What Difference Does It Make? Nurs. Times 1997, 34, 45-46.

16. van Es, S.M. Adherence to Asthma Medication in Adolescents. Ph.D. Thesis, Vrije Universiteit, Amsterdam, 1999.

17. Mesters, I. Infants with Asthma: Towards a Multidisciplinary Education Protocol for Primary Care. Ph.D. Thesis, Rijksuniversiteit Limburg, Maastricht, 1993.

18. Colland, V.T. Leren Omgaan met Astma: Interventiemethoden voor Kinderen en Ouders [Learning to Cope with Asthma: Intervention Programs for Children and Parents]. Ph.D. Thesis, Universiteit van Amsterdam, Amsterdam, 1993.

19. Ghosh, C.S.; Ravindran, P.; Joshi, M.; Stearns, S.C. Reductions in Hospital Use from Self Management Training for Chronic Asthmatics. Soc. Sci. Med. 1998, 8, 1087-1093.

20. Maslennikova, G.Y.; Morosova, M.E.; Salman, N.V.; Kulikov, S.M.; Oganov, R.G. Asthma Education Programme in Russia: Educating Patients. Pat. Educ. Couns. 1998, 33, 113-127.

21. Osman, L.M.; Abdalla, M.I.; Russel, I.T.; Fiddes, J.; Friend, J.A.R.; Legge, J.S.; Douglas, J.G. Integrated Care for Asthma: Matching Care to the Patient. Eur. Resp. J. 1996, 9, 444-448.

22. Campbell Haggerty, M.; Stockdale-Woolley, R.; Nair, S. Respi-care, an Innovative Home Care

Program for the Patient with Chronic Obstructive Pulmonary Disease. Chest 1991, 100 (3), 607-612.

23. Temmink, D.; Hutten, J.B.F.; van der Zee, J.; Huyer Abu- Saad, H. Dutch Nurse Clinics for Children with Asthma: Views of Professionals and Parents. J. Nurs. Care Qual.

1999, 14 (1), 63-71. 